\title{
A MULTI-INSTITUTIONAL INVESTIGATION OF FIRST-YEAR ENGINEERING TUTORIALS: CONTENT, PEDAGOGY, AND EFFECTIVENESS
}

\author{
Shelir Ebrahimi ${ }^{1}$, Chirag Variawa ${ }^{1}$, and, Jeffrey Harris ${ }^{2}$ \\ 1: University of Toronto \\ 2: York University \\ Shelir.Ebrahimi@utoronto.ca
}

\begin{abstract}
For many courses, tutorial classes are important part of students' learning. They are mainly designed to offer students in large classes (usually over 60 students) the opportunity for a more focused discussion and direct engagement with other students and teaching assistants (TAs). Therefore, it is important to make sure tutorial classes address students' needs and reach the effectiveness that is expected from tutorial classes. However, teaching assistants provide essential support roles in the coordination of large undergraduate tutorial classes, but are often overlooked in discussions of pedagogy, both as aspiring teachers and as continuing learners.

In this research, we looked at the overall structure and effectiveness of first-year tutorial classes in design and non-design courses from TA's points of view at two large Canadian universities; the University of Toronto and York University. The intended outcome of this work is to discuss teaching assistants' perceptions on tutorial classes, content and pedagogy of distinctive styles of tutorials, as well as strengths and weaknesses of tutorial classes, and any opportunities for improvement.
\end{abstract}

\section{Keywords: First-Year Engineering, Tutorial Effectiveness, TAs Perception}

\section{INTRODUCTION}

For many courses, tutorial classes are important part of students' learning. They are mainly designed to offer students in classes the opportunity for a more focused discussion and direct engagement with other students and teaching assistants [1] and [2]. Undergraduate engineering education can be well enhanced through the effective use of Teaching Assistants (TAs). Traditionally, TAs have been viewed as support for the instructor, but as studentcentered learning models take more precedence, the role of the TAs is changing to adapt [3] and [4].

Teaching assistants provide essential support roles in the coordination of large undergraduate classes, but are often overlooked in discussions of pedagogy, both as aspiring teachers and as continuing learners [5]. Considering the challenges presented by large class sizes and limited teaching experiences of some TAs, we would like to know how we can effectively enhance undergraduate learning in engineering using tutorial classes.

In most of the literature, tutorial classes have been evaluated from students' points of view [6], [7], and [8]. Although, it is important to know what students think of their tutorial classes, some structural and pedagogical aspects of tutorials cannot be evaluated only by using students' evaluations. Therefore, it is essential to look at the overall structure and effectiveness of tutorial classes from the perspective of TAs who are leading these classes to define the weaknesses and strengths and to provide the opportunity for improvements.

Graduate students play an instructional role providing guidance and feedback on course materials and contents. Although tutorial classes are mainly designed to enhance the learning of undergraduate students, they can also be used as a valuable tool to improve TAs' teaching and communicational skills. Regardless of whether teaching assistants choose a career in academia or elsewhere, tutorial classes can provide valuable potential to develop TAs' skills that are considered employable and transferable. A very well-designed tutorial considers both students and TAs as a center of attention in regard to the effectiveness of tutorials. This is important because designing a tutorial experience which also addresses TAs' needs and expectations can result in more engaged students and teaching assistants, and perhaps more fulfilment, and outcomes. Therefore, it is important to look at the effectiveness of tutorial classes from a different point of view to make sure TAs' needs and expectations are addressed [9], [10] and [11].

Using a case study approach, this paper examines the TAs perception on tutorial structures and effectiveness. In this research, we looked at the tutorial classes in design and non-design courses from TA's points of view at two 
large Canadian universities; the University of Toronto and York University. A combination of a design and a nondesign course covers the most important graduate attributes that should be achieved for first year students. Therefore, looking at these two different styles of tutorials can provide great understanding on the current situation and defining any room for improvements. The primary research questions in this study are:

- How are tutorial classes and TAs' role and responsibilities perceived by TAs?

- What approaches and methods are used by TAs in tutorial classes?

- Are TAs' expectations/perceptions aligned with reality?

In this research, tutorial classes of two diverse types of engineering courses (design and non-design courses) at York University and University of Toronto were investigated during the winter 2018 term, from January 2018 to April 2018. The courses considered in this study are, ENG 1102, "Renaissance Engineer 2: Engineering Design Principles" which is a first-year mandatory course for engineering students in all disciplines at the Lassonde School of Engineering at York University, APS106, "Fundamentals of Computer Programming" and APS 112 "Engineering Strategies and Practice" which are first-year mandatory courses for engineering students in all disciplines in Faculty of Applied Science and Engineering of the University of Toronto. We were unable to study a non-design first-year course at York University due to a labour disruption during the winter 2018 term.

Three different approaches were designed to address research questions: 1) Online survey, 2) Class observations, and 3) interview and focus groups. All of the questionnaires and research methodology were reviewed and approved by the respective ethics review committee at $\mathrm{U}$ of $\mathrm{T}$ and York University.

An 8-question online survey was distributed to TAs to address TAs' perception on tutorial classes. Survey questions focused on TAs' roles and responsibilities inside and outside of classroom. In this survey, both quantitative and qualitative questions were included. Survey-Monkey was used to create the survey as well as part of data analysis.

During the term, tutorial classes of each course were observed 3 times to define the content and pedagogical activities of tutorial classes; as well as performance of TAs in tutorials. Class observation was performed to define the overall structure of tutorial classes. During the class observations some comments were made by the researcher on the following aspects:

- The teaching methods used by the TA (for example: discussion, lecture, demonstration, oneon-one discussion).

- How the TA used technology and the types of technology used.
- The level of thinking that students used in this course (e.g. analyzing ideas, synthesizing ideas, making judgments about information, applying information to new situations).

- How the course content was arranged in a clear, logical and orderly manner.

- How TAs s showed enthusiasm for the subject matter.

- How students were encouraged to ask questions

TAs' focus groups sessions were held twice during the semester to discuss the content, activities and effectiveness of tutorial classes. The following questions were used to facilitate the group discussion:

- Why were you motivated to apply for $1^{\text {st }}$ year TA positions?

- What are your expectations from course instructors?

- In what way should tutorials be different from lectures?

- How have university resources helped you to be successful as a TA?

- Please list and explain the things you found most/least effective, helpful.

- Do you have any concrete suggestions for improvement?

\section{OVERALL STRUCTURE OF TUTORIAL CLASSES}

As part of this study, the overall structures of tutorial classes for a selection of individual courses that are a part of the first-year engineering curriculum were investigated using class observations. During class observations overall performance of TAs, use of teaching methods, use of technology, and techniques to motivate students to participate were investigated to address research question 2. Details of the courses that were analyzed in this research are outlined in Table 1.

Table 1: First-year courses under analysis

\begin{tabular}{|c|c|l|}
\hline $\begin{array}{c}\text { Course } \\
\text { Code }\end{array}$ & Course Name & \multicolumn{1}{c|}{ Description } \\
\hline $\begin{array}{c}\text { APS 106 } \\
\text { U of T }\end{array}$ & $\begin{array}{c}\text { Fundamentals of } \\
\text { Computer } \\
\text { Programming }\end{array}$ & $\begin{array}{l}\text { An introduction to } \\
\text { computer systems } \\
\text { and software which } \\
\text { uses Python as } \\
\text { programming } \\
\text { language }\end{array}$ \\
\hline APS 112 & $\begin{array}{c}\text { Engineering } \\
\text { Utrategies and } \\
\text { Practice }\end{array}$ & $\begin{array}{l}\text { Core course for } \\
\text { engineering } \\
\text { students; focusing } \\
\text { on engineering } \\
\text { design, teamwork, } \\
\text { and communication }\end{array}$ \\
\hline
\end{tabular}




\begin{tabular}{|c|c|l|}
\hline $\begin{array}{c}\text { Course } \\
\text { Code }\end{array}$ & Course Name & \multicolumn{1}{c|}{ Description } \\
\hline & & $\begin{array}{l}\text { This course } \\
\text { provides an } \\
\text { introduction to the } \\
\text { principles \& } \\
\text { practices of } \\
\text { engineering design } \\
\text { focusing on } \\
\text { engineering design }\end{array}$ \\
& & \\
methodology, \\
ENG 1102 & Renaissance & Engineer 2: \\
York & Engineering Design & features and \\
& Principles & elements of good \\
& & design with human \\
& & interface \\
& & considerations, and \\
& & idea \\
& & communication \\
& & using graphics \\
\hline
\end{tabular}

\subsection{Comparison of Design Courses}

Design courses at York University and University of Toronto (U of T) had different styles.

Tutorial classes of the design course at $\mathrm{U}$ of $\mathrm{T}$ worked mainly as a group discussion. Each class had 5 or 6 design groups. This tutorial classes are managed by two TAs called TA and TA manager. TA was responsible to discuss the technical aspects of the project and TA manager was taking care of the management skills (e.g. Gantt chart andstatus reports). In the sessions that were observed, the TAs did not use any technology. Both TA and TA manager met with each group individually. The one-on-one group discussion was very helpful to make students engaged in participation. Also, the discussions were customized for each group based on the submission of previous documents that had been reviewed by both TAs. In this way, students could use the knowledge of TAs fully related to their own projects. On the other hand, time allocation to each group could be a challenge; TAs spent more time with some groups, leaving short amount of time at the end of the class for the others. Also, those groups who had the first discussion time with TAs could use the rest of the class more wisely based on the TAs recommendations.

At York University, the tutorial classes focused more on individual students training on both technical and soft skills. Two TAs managed the tutorials, they used PowerPoint as the main tool to introduce the concepts to students. Sometimes a short video on software training was played in class, paused at different intervals to give students some time to follow the steps. In these classes, a concept (such as individual reflection, Autodesk software) was introduced to students and they were given some time to think and work on the introduced activity. One TA went around the class to answer the questions if they are any while the other TA was taking care of the presentation slides. In the observed classes, there were few group discussions as most of the time students worked individually. Having TAs going around the class and talking to students individually encouraged them to ask their questions. However, if students did not have any questions, they were not forced by the group members or TAs to work during the class. Basically, students had more control of their performances in these tutorial classes.

In the design courses of both institutions, the TAs responsibilities are clearly defined for them; items that they need to address are pre-defined, rubrics are clearly created for the assessments, etc. Generally, there is less room for TAs creativity in terms of the selection of the content that should be taught to students. However, TAs can be still selective in choosing their own style of teaching.

\subsection{Non-Design Course}

The non-design course at the $\mathrm{U}$ of $\mathrm{T}$, APS106 (Computer Programming), focused on developing programming skills. Two TAs managed each tutorial class. This course was highly dependent on use of technology. TAs used PowerPoint slides to introduce the concepts and questions to students. Students were treated individually, TAs went around the class to work individually with students and to address their questions. TAs highly encouraged students to think in different ways of writing a line of programming code to get the same results, so they could understand the performance of each function. Although the tutorial was managed by two TAs, at each specific time, only one of the TAs was actively engaged in teaching the course material. However, each of the TAs offered a different style of teaching and explanation, which was important for a programming course. In this course, although part of tutorial content was provided for TAs, they had a chance to add their own questions and discussions to the tutorial content which provided some room for TAs' creativities.

\section{TA' PERCEPTION ON TUTORIAL}

In order to understand TAs perceptions and expectations of tutorial classes, an online survey was created using Survey-Monkey and was distributed to all of the TAs $(\mathrm{N} \sim 30)$ for selected design and non-design courses via email. A sample of online survey can be found in appendix A. The survey received a $60 \%$ response rate. All of the TAs who responded to the survey have at least the experience of teaching 3 courses (more than 70\% of them have thought more than 5 courses as TA). All of them have the experience of teaching both first year and upper year courses.

First three questions of the survey aimed to analyze the perception of TAs on their responsibilities and required skills as a successful TA. Figure 1 shows the overall 
results of first question: "rank the importance of the skills which helped you succeed as a TA". At U of T, TAs perceive that the most important skills are "problem solving" and "effective communication with instructor", while York University TAs believe that "theoretical/ technical knowledge" and "leadership" are the most important skills for a successful TA.

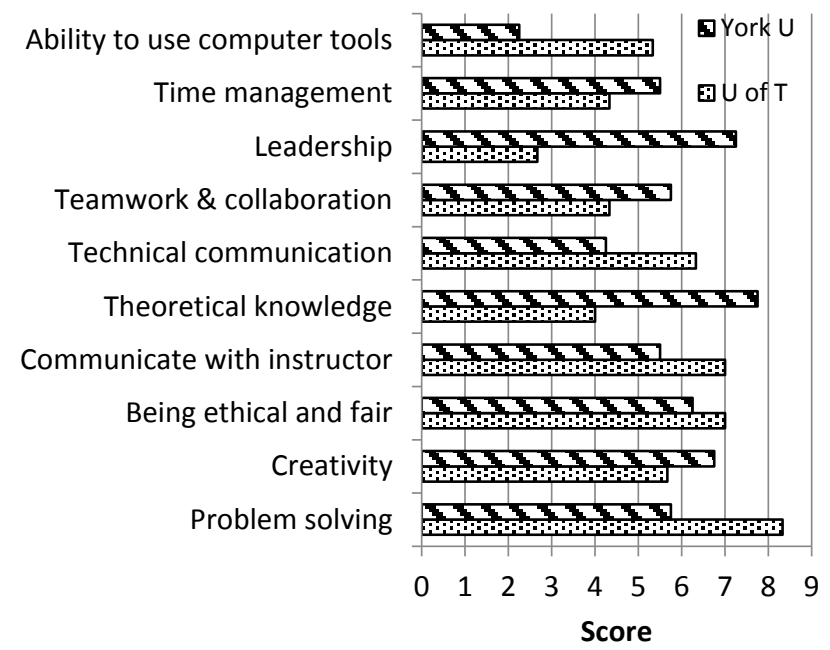

Fig. 1. Ranking of the importance of the skills which helped TAs to succeed (Question 1)

Based on question 2 and per as the survey results of both institutes, "going through selected examples" and "facilitate class conversations" are important responsibilities for TAs during tutorial classes at York Universit;, while at U of T, "helping students one by one" and "facilitating" class conversations are the most important (figure 2). On the other hand, the main responsibilities outside classrooms for York TAs are tutorial preparation and marking assignments while for $\mathrm{U}$ of $\mathrm{T}$, holding office hours has the highest rank and tutorial preparation and communicate with students through email are the second important responsibilities (Figure 3).

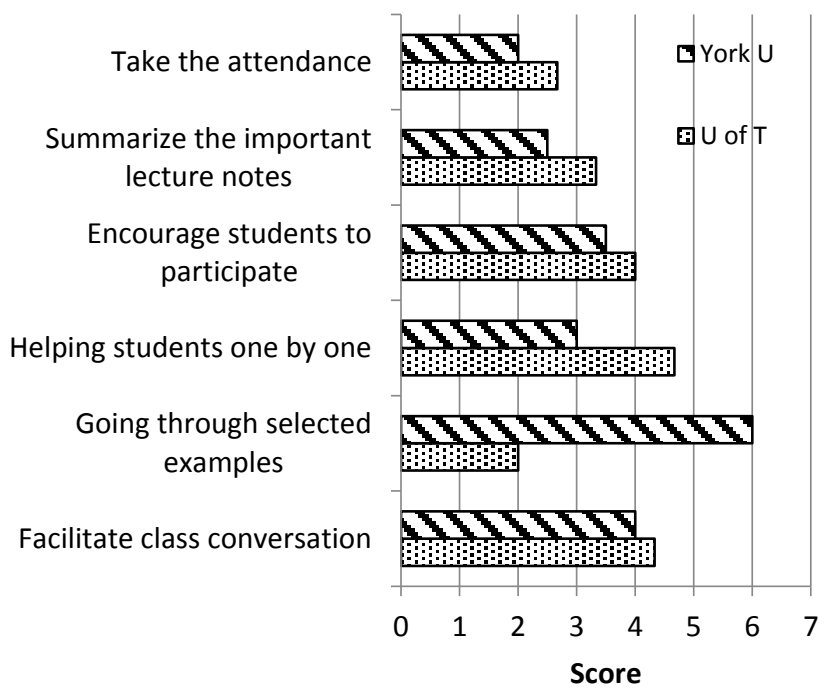

Fig. 2. Main TAs responsibilities during tutorial classes (Question 2)

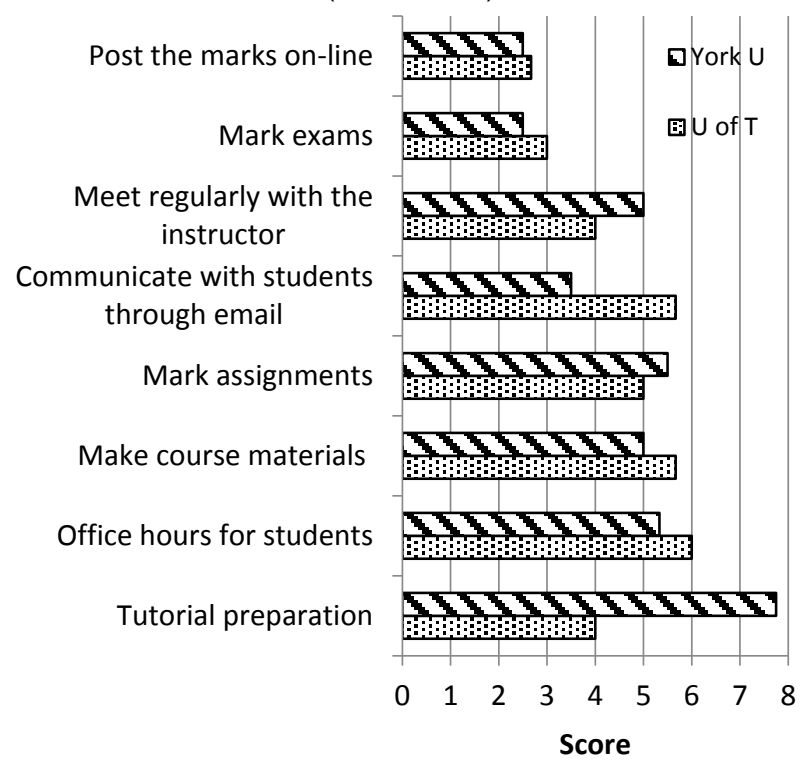

Fig. 3. Main TAs responsibilities outside tutorial classes (Question 3)

Regarding the difference of the provided answers by TAs of two institutions, I would like to make an additional point for consideration, which is that at York University, TAs do not create the course content for their tutorials, but are instead provided with the material by the course instructors, which leaves the TA with limited ability to act independently. However, at the courses observed at the University of Toronto, TAs were given more flexibility in terms of class contents that should be covered, especially in non-design courses.

Question 4 of the survey looked at the reasons for which TAs accept their teaching positions. We wanted to know what motivates TAs to apply for this position and what they are hoping to get out of this experience. Figure 4 presents the results of the survey for this question.

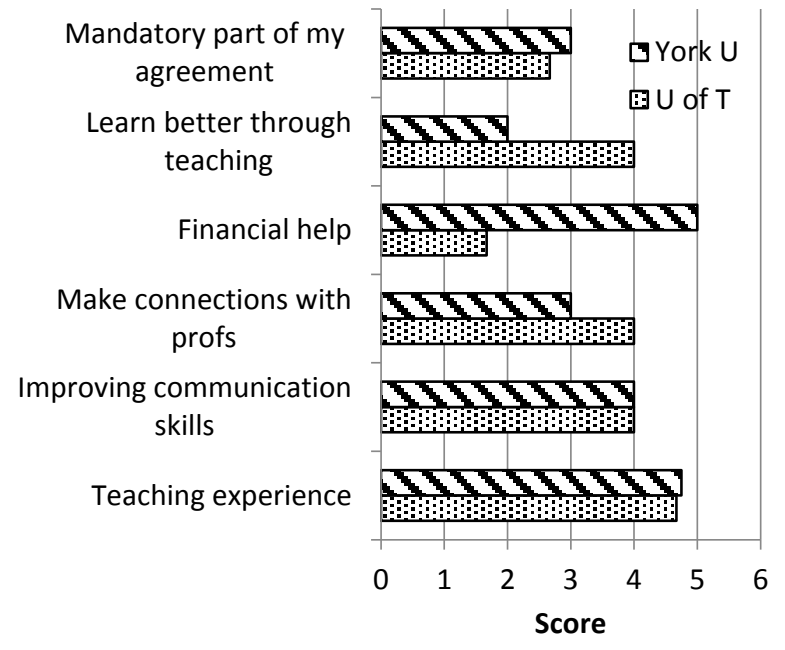

Fig. 4. The most important reason for which TAs accept their position (Question 4) 
As it can be seen from figure 4, at York University, financial help and teaching experience were top two answers. At $\mathrm{U}$ of $\mathrm{T}$, the top reason for accepting a TA position was teaching experience. Improving communication skills, make connection with instructors, and learn better through teaching, were all ranked the same as the second important motivating reason to accept a TA position at $\mathrm{U}$ of $\mathrm{T}$.

Questions 7 and 8 of the survey focused on the TAs understanding of the differences between teaching first year and upper year courses. $80 \%$ of the TAs of both institutes thought that teaching a first-year class is more difficult than teaching an upper-year course. They strongly believe that "self-learning" skill of students is the most different aspect of teaching a first-year and an upper-year class. This was expected as mostly first year students do not know how to learn by themselves and their learning process can be highly dependent on attending lectures, and tutorial cases. They also believe that first year students are less mature and less responsible which makes teaching first-year classes harder than upper-year ones.

\section{ALIGNMENT OF REALITY AND PERCEPTION}

Overall three TAs focus group discussions and two interviews were performed during the semester. This section summarizes the important points that have been mentions by TAs.

\subsection{Tutorial Flexibility}

Having flexibility as a TA (giving a chance by instructor so TAs can make their own course materials and teach in their own preferred ways), provides an opportunity for teaching creativity. However, if it is not organized well, it might result in inconsistency between tutorials. In order to address the creativity aspects while keeping the consistency of tutorials, $2 / 3$ of tutorial content can be designed by instructors and provided to TAs to make sure important aspects of the course will be addressed in tutorials no matter who is teaching a tutorial. Leaving $1 / 3$ of class content to be designed by TAs motivated them to be creative in their teaching styles. This approach looks at TAs more as an instructor rather than deliverer which gives them a sense of ownership as well.

\subsection{Regular Meetings}

Having regular weekly meetings is highly recommended by TAs. These meetings provide an opportunity for them to share their challenges and to make the responsibilities and expectations very clear.

Some TAs think, instructor expectations on the amount of time that should be spent on each task must be clear; e.g. marking a specific assignment. This is a key for those TAs who are teaching course for the first time.

Also, having regular meeting or a virtual group (using a phone app) would help to coordinate between TAs to make sure tutorial classes are consistent regardless of which TA is teaching it.

\subsection{TAs Training}

There are two sides on the topic of TA training: 1) create a minimum standard for all of the TAs, 2) Improve the teaching skills of those TAs who are highly interested in learning more about teaching learning development and teaching methodologies in general. Most of the TAs think one day training at the beginning of the term along with weekly meetings are good enough to discuss some aspects of teaching styles and there is no need of extra formal training.

On the other hand, those TAs who accept the position to improve their own personal skills and those TAS who are seeking to get a teaching position in future are interested in having more formal TA training sessions.

\section{CONCLUSION ROOM FOR IMPROVMENTS}

It is more common to ask students questions about tutorials effectiveness in teaching evaluation surveys, but looking at the effectiveness of tutorials from TAs point of view along with teaching evaluations by students is a more holistic approach which yields in interesting information for instructors and curriculum designers.

This exploratory research is a first-step towards better understanding the first-year engineering tutorial experience, from the perspectives of graduate student teaching assistants. This work showed that in observed tutorial classes at the University of Toronto:

- Design course tutorials are group-discussionbased and do not rely on use of technology.

- TAs do not play any role in the material selection of tutorials; everything is very-well pre-defined.

- In non-design tutorials, TAs are partially responsible in preparing class materials which provide more freedom and flexibility that can results in teaching creativity.

- From TAs point of view, the most important skills that required to be successful as a TA are "problem solving" and "effective communication with instructor".

- "Helping students one by one" and "facilitate class conversations" are the most important TAs' responsibilities during the class. As outside class room responsibilities, "holding office hours" has the highest rank and "tutorial preparation" and "communicate with 
students through email" are the second important ones.

- "Teaching experience", "Improving communication skills", "make connection with instructors", and "learn better through teaching", the important motivating reason to accept a TA position.

Also, this research showed that in observed design tutorial classes at York University:

- Tutorials rely heavily on the use of technology.

- TAs are provided with course materials but they can be creative in using different teaching methods.

- TAs believe "theoretical/ technical knowledge" and "leadership" are the most important skills for a successful TA to have.

- "Going through selected examples" and "facilitate class conversations" are important TAs responsibilities during tutorial classes at while "tutorial preparation" and "marking assignments" are the main responsibilities outside classrooms.

- The main reasons to accept TA position are "financial help" and "teaching experience"

Also this study showed that having regular meeting during a semester and well-designed TA training programs could be beneficial for TAs to improve tutorials quality as well as TAs professional skills.

The results of this research are helpful for thinking of new ways to modify tutorial classes if it is required, to design new learning activities for design and non-design tutorial classes, and to organize new workshops for training TAs.

\section{Acknowledgements}

The authors would like to acknowledge all of the TAs and instructors who participated in this research as well as the support of the Faculty of Applied Science at the University of Toronto and Lassonde School of Engineering at York University

\section{References}

[1] Rosales J. Caines S. Spracklin-Reid D, "Effective use of graduate students as teaching assistants in undergraduate engineering education, " in Proc. CEAA Canadian Engineering Education Association Conf., CEEA13. 2013.

[2] Sargent L.D. Allen B. C. Frahm. Morris G, "Enhancing the experience of student teams in large classes : Training teaching assistants to be coaches, "
Journal of Management Education, vol. 33, no. 5, pp. 526-552, 2009.

http://journals.sagepub.com/doi/abs/10.1177/1052562 909334092

[3] Samson s. Millet M, "The learning environment: Firstyear students, teaching assistants, and information literacy," Research Strategies, vol 19, pp. 84-98, 2003.

https://www.sciencedirect.com/science/article/pii /S073433100400014X

[4] Centra J. A. Creech F. R, "The relationship between student teachers and course characteristics and student ratings of teacher effectiveness," (Project Report 761). Princeton, NJ. Educational Testing Service. 1976.

[5] Iaria G. Hubball, H, "Assessing Student Engagement in Small and Large Classes," Transformative

Dialogues: Teaching \& Learning Journal, vol. 2, no. 1, pp. 1-8. 2008. http://www.neurolab.ca/2008(11) Iaria.pdf

[6] Gleeson A. McDonald J. Williams J, "Students perception of the effectiveness of collaborative learning," Flinders Business School Research Paper Series: vol. 5. 2007, http://www.flinders.edu.au/sabs/business/researc $\mathrm{h} /$ papers/07-05.pdf

[7] Centra J. and Gaubatz N, "Students perceptions of learning and instructional effectiveness in college courses," ETS Student Instructional Repor. $t 2005$. https://www.ets.org/Media/Products/perceptions. pdf

[8] Al-Nassar S. McBean E. Lennox W. C, "Student Evaluation of the Tutorial System in Engineering Programmes," European Journal of Engineering Education, Vol. 12, no. 4, pp. 343-352. 2007. https://www.tandfonline.com/doi/abs/10.1080/030437 $\underline{98708939381}$

[9] Kerr A, "Teaching and Learning in Large Classes at Ontario Universities: An Exploratory Study," Higher Education Quality Council of Ontario, () Queens Printer for Ontario, 2011.

http://www.heqco.ca/SiteCollectionDocuments/Teachi ng\%20and\%20Learning\%20in\%20Large\%20Classes \%20ENG.pdf

[10] Gaff, J.G, "The Disconnect Between Graduate Education the Realities of Faculty Work: A Review of Recent Research," Liberal Education, vol. 88, no. 3, pp. 1-11. https://www.aacu.org/publicationsresearch/periodicals/disconnect-between-graduateeducation-and-realities-faculty-work

[11] Weber R. J. Gabbert A. Kropp J. Pynes1 P, “Creating the Teaching Professor: Guiding Graduate Students to Become Effective Teachers," The Journal of Scholarship of Teaching and Learning, Vol. 7, no. 1, pp. 45-63, 2007. https://files.eric.ed.gov/fulltext/EJ854934.pdf 


\section{APPENDIX A: SAMPLE OF ONLINE SURVEY}

Please answer the following questions to the best of your knowledge.

- Ranking scale: $(1=$ Most important, with each following value indicating decreasing importance)

- Do not rank an item if you think it is not applicable.

- Items can not have shared rankings.

1. Please rank the importance of the following skills which helped you succeed as a TA.

- Teamwork and collaboration

- Leadership

- Ability to understand and use and teach theoretical/technical knowledge of the course

- Time management

- Technical communication (e.g. writing a report, presentation)

- Ability to use computer tools.

- Being ethical and fair

- Problem solving

- Creativity

- Effective communication with course instructor

- Understanding expectations set by the instructor

- University blackboard/portal

2. Please rank the importance of the following items as the main responsibilities of a TA during the tutorial class?

- Facilitate class conversation

- Going through selected examples

- Helping students one by one

- Encourage students to participate

- Summarize the important lecture notes

- Take the attendance

3. Please rank the importance of the following items as the main responsibilities of a TA outside the classroom

- Meet regularly with the instructor

- Office hours for students

- Make course materials for tutorial classes

- Tutorial preparation

- Mark assignments

- Post the marks on-line

- Communicate with students through email
- Mark exams

4. Please rank the importance of the following items as the most important reason for which you accepted TA positions

- Teaching experience

- Financial help

- Improving communication skills (personal development)

- Make connections with profs

- Learn better through teaching

- Mandatory part of my agreement (contractually obligated)

- Others (please specify)

5. Did you receive any training regarding teaching a tutorial class?

- $\mathrm{Yes} / \mathrm{No}$

6. How many courses have you taught as a TA so far (including this semester)?

7. If you have the experience of teaching both 1st year and upper year tutorials, in which way teaching a first year tutorial is different from upper year tutorials? (Choose from the most different to the least different)

- Maturity

- Responsibility

- Self-learning

- Manageable/controllable

- Easy to communicate

- Demanding

8. If you have the experience of teaching both 1st year and upper year tutorials, overall, how difficult is teaching a first year tutorial compare to upper year's tutorials?

- Very easy

- Easy

- No difference

- Difficult

- Very difficult 